\title{
Analisis Hukum Islam terhadap Perubahan Fatwa Mui Tahun 1979,2009,2012 tentang Penggunaan Alat Kontrasepsi Vasektomi
}

\author{
Selfi Wahyu Putri* \\ Prodi Hukum Keluarga Islam, Fakultas Syariah, Universitas Islam \\ Bandung, Indonesia. \\ *selfiwahyuputri@gmail.com
}

\begin{abstract}
The background of this research is the MUI Fatwa on the use of vasectomy contraception which is one of the discussions that attracts attention. Starting from the concept of giving a fatwa according to the view of Islamic law, changing the fatwa on the use of vasectomy contraception to become a permissible fatwa, to the analysis of Islamic law on changes to the vasectomy fatwa which changed up to 4 times over a period of 30 years. The purpose of this research is to answer the existing problem formulation, namely to find out how the concept of fatwa is based on Islamic law, to find out the change in the fatwa from haram to permissible in the 2012 MUI fatwa on vasectomy, and to find out how Islamic law analyzes the changes in the MUI fatwa regarding the use of vasectomy. vasectomy. This research is a qualitative research which in this study used the normative juridical research method. This research uses the type of literature study research. The data used in this study are primary and secondary data, and the technique used in collecting data is library research. The data analysis technique used is descriptive and deductive technique. The results of this study can be concluded that the fatwa changes made by the Indonesian fatwa institution, better known as the Indonesian Ulema Council, are things that are allowed in religion. Because basically the law may change and there are several factors that cause a change in the law itself, namely the time factor, the place factor, the condition factor, the intention factor, the tradition factor.
\end{abstract}

Keywords: Islamic Law, MUI Fatwa, Changes to Vasectomy Fatwa.

\begin{abstract}
Abstrak. Penelitian ini dilatar belakangi dari Fatwa MUI terhadap penggunaan alat kontrasepsi vasektomi yang menjadi salah satu pembahasan yang menarik perhatian. Mulai dari konsep berfatwa menurut pandangan hukum Islam, perubahan fatwa haram penggunaan alat kontrasepsi vasektomi menjadi fatwa boleh, hingga analisis hukum Islam terhadap perubahan-perubahan fatwa vasektomi yang berubah hingga 4 kali selama kurun waktu 30 tahun. Tujuan dilakukannya penelitian ini adalah sebagai jawaban dari rumusan masalah yang ada yaitu untuk mengetahui bagaimana konsep berfatwa menurut hukum Islam, untuk mengetahui perubahan fatwa haram menjadi boleh pada fatwa MUI tahun 2012 tentang vasektomi, dan untuk mengetahui bagaimana analisis hukum Islam terhadap perubahan fatwa MUI tentang penggunaan vasektomi. Penelitian ini merupakan penelitian kualitatif yang mana dalam penelitian ini digunakan metode penelitian Yuridis Normatif. Penelitian ini menggunakan jenis penelitian Studi Pustaka. Data yang digunakan dalam penelitian ini primer dan data sekunder, dan Teknik yang digunakan dalam mengumpulkan data adalah penelitian Pustaka. Teknik analisis data yang digunakan adalah Teknik deskriptif dan deduktif. Hasil dari penelitian ini dapat dikesimpulan bahwa perubahan-perubahan fatwa yang di lakukan oleh Lembaga fatwa Indonesia yang lebih dikenal dengan Majelis Ulama Indonesia ini merupakan hal yang diperbolehkan dalam agama. Karna pada dasarnya hukum boleh berubah dan ada beberapa faktor yang menyebabkan terjadinya perubahan hukum itu sendiri, yaitu faktor waktu, faktor tempat, faktor kondisi, faktor niat, faktor tradisi.
\end{abstract}

Kata Kunci: Hukum Islam, Fatwa MUI, Perubahan Fatwa Vasektomi. 


\section{A. Pendahuluan}

Perkawinan adalah suatu perjanjian suci antara seorang laki-laki dan seorang perempuan untuk membentuk keluarga bahagia menurut Abdurrahman Al-Jaziri. Dari uraian diatas memperjelas bahwa perjanjian ini sendiri mempunyai makna sebagai suatu keinginan yang bersifat bebas antara kedua belah pihak yang saling berjanji serta bersumber pada prinsip suka sama suka tanpa adanya paksaan.

Dalam ajaran Islam pernikahan merupakan sunnah yang dianjuarkan Rasulullah untuk mendapat ridho Allah dan mencapai keluarga yang sakinah, mawaddah, warahmah. Selain untuk mendapatkan ridho dari Allah, pernikahan juga bertujuan untuk memperoleh keturunan.

Jika di lihat dari konteks pertumbuhan penduduk di Indonesia yang mana perbandingan antara luas wilayah tidak sebanding dengan pertumbuhan penduduknya yang menyebabkan terjadinya kepadatan penduduk di Indonesia. Hal inilah yang membuat pemerintah Indonesia mengambil alternatif untuk mengurangi jumlah kepadatan penduduk dengan cara mengurangi angka kelahiran, yaitu dengan diadakannya program Keluarga Berencana (KB).

Pada Tahun 1970 pemerintah Indonesia mulai memperkenalkan istilah Keluarga Berencana (KB) sebagai suatu gerakan untuk membentuk keluarga yang sehat dan sejahtera dengan membatasi kelahiran. Program Keluarga Berencana ialah salah satu upaya pemerintah Indonesia yang ditangani oleh Badan Kependudukan dan Keluarga Berencana Nasional (BKKBN) Keluarga Berencana (KB) memiliki beberapa metode dalam pelaksanaannya, dan yang paling menarik perhatian dari pandangan hukum Islam dengan cara sterilisasi (vasektomi dan tubektomi).

Pengertian Sterilisasi pada laki-laki disebut vasektomi atau Vas Ligation. Vasektomi ialah memandulkan laki-laki dengan cara melakukan operasi (pada umumnya) agar tidak dapat menghasilkan keturunan. Sterilisasi berbeda dengan cara alat-alat kontrasepsi lainnya yang hanya bertujuan menghindari/menjarangkan kehamilan untuk sementara waktu.

Selain mengenai fatwa Keluarga Berencana, persoalan hukum vasektomi juga mendapat perhatian dari MUI, karena selama kurun waktu lebih kurang 30 tahun (1979 sampai dengan 2012) ditetapkan hukumnya dalam bentuk fatwa MUI sebanyak empat kali. Tiga kali fatwa dinyatakan haram dan yang terakhir dinyatakan haram kecuali keadaan memenuhi syarat dan terakhir menegaskan kebolehan (ibāhah) vasektomi dengan syarat.

Berdasarkan pemaparan persoalan mengenai vasektomi diatas, penulis merasa penting untuk mengetahui secara detail lagi melalui penelitian akademik guna mendapatkan gambaran yang sebenarnya. Maka dilakukan penelitian dengan judul "Analisis Hukum Islam terhadap Perubahan Fatwa MUI Tahun 1979, 2009, 2012 tentang Penggunaan alat Kontrasepsi Vasektomi" dengan tujuan penelitian:

1. Untuk mengetahui bagaimana konsep berfatwa menurut hukum Islam.

2. Untuk mengetahui perubahan fatwa haram menjadi boleh pada fatwa MUI tahun 2012 tentang vasektomi.

3. Untuk mengetahui bagaimana analisis hukum Islam Terhadap perubahan fatwa MUI tentang penggunaan vasektomi.

\section{B. Metodologi Penelitian}

Penelitian ini menggunakan metode penelitian yuridis normatif, dengan menggunakan pendekatan penelitian kualitatif. Pada penelitian ini penulis menggunakan jenis penelitian Studi Kepustakaan (Library Research).

Sumber data yang di gunakan dalam penelitian ini adalah sumber-sumber yang telah ada dari barbagai literatur, baik itu berupa hasi wawancara, buku, internet, dan jurnal memiliki hubungan atau berkaitan dengan penelitian.

1. Sumber Data Primer

Adapun data primer yang digunakan adalah fatwa-fatwa MUI mengenai vasektomi. Serta Al-quran dan Hadist

2. Sumber data sekunder

Adapun data sekunder yang di gunakan dalam penelitian ini adalah hasil dari, buku, dan jurnal yang memiliki hubungan atau keterkaitan dengan penelitian. 
Metode pengumpulan data dalam penelitian ini merupakan penelitian kepustakaan, dengan teknis analisis deskriptif dan deduktif.

\section{Hasil Penelitian dan Pembahasan}

\section{Analisi Hukum terhadap Perubahan Perubahan Fatwa MUI tentang Vasektomi}

Perubahan fatwa vasektomi telah terjadi beberapa kali. Pertama, di tahun 1979, merupakan masa-masa awal gencarnya program Keluarga Berencana, MUI memfatwakan keharaman vasektomi dengan dua alasan pokok, yaitu 1) vasektomi adalah bentuk usaha pemandulan, sedangkan pemandulan dilarang dalam agama Islam; 2) di Indonesia belum dapat dibuktikan bahwa vasektomi itu sendiri dapat disembuhkan kembali. Kedua, pada tahun 1983, pada forum Musyawarah Nasional tentang kependudukan, kesehatan dan pembangunan, tanggal 17-30 Oktober 1983, MUI kembali menegaskan keharaman vasektomi dan tubektomi menguatkan fatwa tahun 1979. Ketiga, pada bulan Januari 2009 dilaksanakan forum ijtimā' ulama komisi fatwa MUI ketiga. Sementara, pemerintah menganggap salah satu hambatan program KB pria (vasektomi) adalah fatwa MUI yang mengharamkan vasektomi.

Keempat, diselenggarakan forum ijtimā' ulamat, pada bulan Juni/Juli 2012 di Cipasung Tasikmalaya. Pemerintah kembali mengajukan dan menguatkan argumentasi berkaitan dengan bukti keberhasilan rekanalisasi (Surat Kementerian Kesehatan Republik Indonesia, No. TU.05.02/V/1016/ 2012, tanggal 11 Juni 2012, tentang Permohonan Peninjauan Vasektomi). Maka melalui kajian baru yang dianggap sebagai 'illat hukum vasektomi, ijtimā ulama menetapkan fatwa vasektomi "haram kecuali...." atau "mubah dengan syarat...." berjalannya proses ijtima' ulama ini memakan waktu selama kurang lebih satu tahun.

Metode yang digunakan MUI dalam mengeluarkan fatwa:

1. Setiap keputusan yang dikeluarkan oleh MUI harus mempunyai dasar atas Kitabullah dan Sunnah Rasul yang mu'tabarah dan tidak bertentangan dengan kemaslahatan masyarakat.

2. Jika dalam Kitabullah dan Sunnah Rasul tidak terdapat jawaban dari pertanyaan, sebagaimana ditentukan di atas, maka keputusan fatwa harus diambil dengan cara yang tidak bertentangan. Bisa menggunakan cara Ijma', Qiyas yang Mu'tabar dan dari dalildalil hukum yang lainnya seperti: Istihsan, Maslahah Mursalah dan Sadd azzari'ah.

3. Sebelum MUI pengambilan keputusan fatwa, dianjurkan untuk mengkaji pendapatpendapat para imam mazhab yang terdahulu, baik yang berhubungan dengan dalil-dalil hukum maupun yang berhubungan dengan dalil-dalil yang dipergunakan oleh pihak yang berbeda pendapat. Jika dalam hal ini material hukumnya berbeda, maka yang ditempuh adalah menganalogikan hukum material yang telah diputuskan ulama madzhab dengan mendeteksi kesamaan illatnya. Adapun jika tidak memungkinkan, maka metodologi para imam madzhab diadopsi menjadi pisau analisis untuk memecahkan persoalan yang sedang dikaji.

4. Pandangan para ahli dalam bidang masalah yang akan diambil keputusan fatwanya haruslah dipertimbangkan dengan matang disesuaikan dengan bidang kajian para ahli tersebut.

\section{Metode yang digunakan MUI dalam penetapan Fatwa tentang Vasektomi}

Berdasarkan data penetapan hukum vasektomi yang diambil dari dalil-dalil Al-Quran, Hadist dan Kaidah Fikih maka dari sini dapat disimpulkan bahwa metode yang di gunakan MUI dalam menetapkan fatwa tentang vasektomi adalah menggunakan metode Qiyas yang mana menyamakan illat vasektomi dengan:

1. Membunuh anak yang terdapat dalam QS. Al-An'am ayat 151, QS Al-Isra' ayat 31, dan QS Al-An'am ayat 137

2. Mengubah ciptaan Allah yang terdapat dalam QS. An-Nisa ayat 119

3. Mengubur anak perempuan hidup-hidup terdapat dalam hadis Rasulullah yang di riwayatkan oleh Ad-Darimi.

4. Memendekkan rambut bagi kaum wanita hingga menyerupai laki-laki dan membuat tato hingga mengubah ciptaan Allah terdapat dalam hadis Rasulullah yang di riwayatkan oleh 
Imam Ahmad

Selain menggunakan metode Qiyas, MUI juga menggunakan metode Ijma' dalam penetapan hukum vasektomi. Kesepakatan para mufti terhadap hukum vasektomi sebagai berikut:

1. Vasektomi boleh dilakukan untuk tujuan yang tidak menyalahi syari'at Islam

2. Vasektomi boleh dilakukan jika tidak menimbulkan kemandulan permanen bagi yang melakukan vasektomi

3. Ada jaminan dapat dilakukannya rekanalisasi yang dapat mengembalikan fungsi organ reproduksi seperti semula sehingga pasien bisa membuahi kembali dan memiliki keturunan lagi.

4. Tidak menimbulkan bahaya (mudlarat) bagi pasien yang melakukan vasektomi, dan

5. Tidak dimasukkan ke dalam program dan metode kontrasepsi mantap.

\section{Konsep Kontrasepsi Vasektomi menurut Hukum Islam}

Kontrasepsi vasektomi menurut hukum Islam pada dasarnya adalah haram atau di larang oleh syariat islam, Karena ada beberapa hal yang prinsipil, yaitu:

1. Kontrasepsi vasektomi mengakibatkan kemandulan tetap bagi pasien kontrasepsi vasektomi.

2. Mengubah ciptaan Allah SWT dengan melakukan pemotong dan menghilangkan bagian tubuh yang sehat dan berfungsi (saluran mani).

Selain metode yang di atas MUI juga mengakui berbagai sumber dari kalangan ulama (Al-Mukhtalaf fiha) tentang dapat atau tidaknya metode tersebut dipergunakan dalam memutuskan hukum pada suatu masalah. Di antaranya yang disebutkan dalam keputusan MUI di atas adalah konsep Istihsan, maslahah dan sadd adz-zariah. Namun, MUI memakai semua konsep metode almukhtalaf fiha dalam pengistinbatan hukum terhadap suatu masalah yang akan difatwakan, sesuai dengan kebutuhan dan kemashlahatannya.

Selain itu MUI juga mempertimbangkan dan bahkan mengkaji kembali berbagai pendapat yang telah disampaikan oleh para imam mazhab terkemuka dalam satu persoalan hukum yang memiliki kaitan dengan masalah yang akan difatwakan oleh MUI, baik dari segi dalil-dalilnya dan argumentasinya yang menentang maupun yang mendukung gunanya untuk disimpulkan mana yang lebih kuat di antara keduanya (ditarjih).

Selain itu MUI juga menggunakan metode pengambilan fatwa Qawaid fiqhiyyah di dalam beberapa fatwa MUI itu sendiri. Dalam konsiderat Fatwa MUI, bagian fatwa yang memuat kaidah fiqhiyyah adalah pada bagian kedua dari konsideran fatwa yaitu di bagian "mengingat":

1. Pada bagian ini Al-Quran merupakan sumber utama.

2. Mengutip dari hadis Rasulullah saw.

3. Melandaskan pada metode istinbat hukum atau adillah al-Ahkam baik yang disepakati oleh para ulama atau pun yang tidak disepakati oleh ulama, yang merupakan objek kajian ushul fikih.

Mengutip dari kaidah-kaidah fiqhiyyah yang relevan dengan permasalahan yang akan dikaji dan akan dikeluarkan fatwanya.

Menurut pandangan hukum Islam sebenarnya setiap hukum itu dapat berubah. Aspekaspek yang mempengaruhi perubahan hukum:

1. Waktu

2. Ruang

3. Keadaan

4. Motif

5. Tradisi

Pandangan Para Ulama terhadap Penggunaan Alat Kontrasepsi Vasektomi

Para ahli fikih memiliki pandangan yang berbeda akan hukum penggunaan alat kontrasepsi vasektomi, ada tiga pandangan ahli fikih terhadap hukum penggunaan vasektomi.

1. Yang mengatakan haram secara mutlak

Salah satu ulama yang mengatakan hukum vasektomi atau KB secara umum adalah 
haram ialah Abu Zahrah. Abu Zahra merupakan salah satu dosen bersar di Universitas Kairo.

2. Yang mengatakan boleh secara mutlak

Para penganut mazhab Imāmiyah membolehkan penggunaan sterilisasi secara permanen, Shaykh M. Shamsuddin yang merupakan salah satu ulama dari kalangan Shī'ah Imāmiyah mengungkapkan pembolehannya di dalam Konferensi Rabat.

Beliau mengungkapkan bahwa "Ketika menguji sumber-sumber hukum kami tentang penggunaan sterilisasi, kami mendapatkan bahwa tidak ada sesuatu yang mencegah si suami dan si istri untuk menjalani operasi (untuk sterilisasi) semacam itu (vasektomi dan tubektomi), Hukum Islam tidak membebankan kewajiban pemeliharaan kemampuan untuk berkembang, dan bukan suatu hak perkawinan. Karena itu, secara hukum diizinkan untuk menjalani operasi pembedahan (atau lainnya) untuk mensterilkan lelaki (vasektomi) atau perempuan (tubektomi), baik ada kemungkinan untuk keduanya kembali subur ataupun tidak."

3. Yang membolehkan jika tidak menimbukkan kemandulan yang permanen Syeh Jād al-Haq salah satu mufti besar mesir berpendapat bahwa sterilisasi tidak diizinkan apabila menyebabkan seseorang menjadi kehilangan kesuburannya secara permanen, baik yang melalui pembedahan (operasi) ataupun yang melalui obat-obatan. Sterilisasi pada dasarnya boleh digunakan apabila dilakukan karena adanya suatu penyakit yang telah diketahui secara pasti dan berakibat bisa diturunkan atau akan menular kepada keturunannya (menyebabkan sakit). Dalam hal demikian, sterilisasi menjadi wajib. Pembolehan ini didasarkan pada prinsip juristik yang mengizinkan kemadaratan untuk mengelakkan kemudaratan yang akan di timbulkan lebih besar lagi.

Selain Syeh Jad Al-Haq, Shaykh Shalțūt juga memiliki pendapat yang sama. Bahwa sterilisasi haram hukumnya kecuali di lakukan pada situasi-situasi serius yang menyangkut penyakit keturunan atau yang mungkin menula.

\section{Kesimpulan}

Berdasarkan hasil penelitian yang telah dilakukan oleh penulis terhadap perubahan fatwa MUI tentang alat kontrasepsi vasektomi maka dapat ditarik kesimpulan sebagai berikut ini:

1. Konsep fatwa dalam hukum Islam bersumber kepada Al-Quran, Hadist, Ijma', Qiyas, Istihsan, Al-Istishhab, Syar'u Man Qablana, Metode Ijtihad Kontemporer, dan konsep ini jugalah yang digunakan dan menjadi pedoman bagi MUI untuk mengeluarkan fatwa untuk jawaban dari pertanyaan umat muslim.

2. Perubahan fatwa haram menjadi boleh pada fatwa penggunaan alat kontrasepsi vasektomi didasari pada adanya pembuktian bahwa vasektomi bisa disembuhkan kembali dan tidak menyebabkan kemandulan permanen bagi pasien yang melakukan vasektomi. Pada dasarnya menurut ajaran islam fatwa memang dapat berubah, ada 5 faktor penting yang dapat menyebabkan perubahan fatwa, yaitu: Al-Azminah (waktu), Al-Amkinah (ruang), Alahwal (keadaan), An-Niyyat (motivasi) dan Al-Awa'id (tradisi).

3. Perubahan fatwa tentang penggunaan alat kontrasepsi vasektomi pada dasarnya menurut agama Islam itu boleh-boleh saja dilakukan jika ditinjau dari faktor waktu, ruang (tempat), motifasi, keadaan, tradisi, dan dikaji bagaimana Illat hukumnya. Illat vasektomi disamakan dengan membunuh anak, sementara keluar fatwa beleh karna sudah adanya pembuktian bahwa vasektomi dapat disembuhkan.

\section{Acknowledge}

Dalam hal ini, penulis menyadari bahwa selama proses penulisan skripsi ini penulis banyak mendapatkan bantuan tenaga, materi, informasi, waktu, maupun dorongan yang tidak terhingga dari berbagai pihak. Karena itu, dengan tulus penulis mengucapkan terima kasih yang tak terhingga kepada:

1. Kedua orang tua tercinta yang telah memberikan motivasi, semangat, kasih sayang dan doa yang tak pernah putus kepada penulis, terima kasih dan maaf yang tak terhingga, semoga Allah SWT memuliakan. Sembah sujud untuk kedua orang tua penulis. 
2. Kakak-kakak penulis kepada kakak pertama Sulfana Menggano,AM.d, kakak kedua Solfia Bramo, kakak ketiga Silfana Midona,AM.d, kakak keempat Syafrianto yang telah memberikan semangat, motivasi, dukungan, dan doa untuk adiknya.

3. Kakak ipar penulis Afrizal yang telah menganggap penulis seperti adik kandungnya sendiri dan selalu memberikan motifasi dan semangat kepada penulis selama penulis menyelesaikan skripsi penulis.

4. Keponakan penulisa Stevani Arrazak, Syahla Adiba Bilbina, Sean Vito Alfatih yang menjadi semangat penulis untuk menyelesaikan skripsi penulis.

5. Ibu Titin Suprihatin, Dra., M.Hum. selaku Dekan Fakultas Syariah Universitas Islam Bandung.

6. Bapak Encep Abdul Rojak, S.H.I., M.Sy selaku ketua program studi Ahwal AlSyakhsiyyah

7. Bapak Dr. Ramdan Fawzi, S.H.I.,M.Ag selaku dosen pembimbing I yang telah mau memberikan waktunya dan pikirannya dalam membantu penulis menyelesaikan skripsi ini semoga Allah SWT senantiasa memberikan berkah dan karunia-Nya bagi bapak dan keluarga.

8. Bapak Muhammad Yunus, S.H.I.,M.E.Sy selakukan dpsen pembimbing II yang telah mau memberikan waktunya dan pikirannya dalam membantu penulis menyelesaikan skripsi ini semoga Allah SWT senantiasa memberikan berkah dan karunia-Nya bagi bapak dan keluarga.

9. Bapak Dr. Amrullah Hayyatudin, S.H.I.,M.Ag selaku dosen wali penulis yang telah membantu selama 3,5 tahun.

10. Kepada dosen dan staff Fakultas Syariah yang telah membantu selama perkuliahan.

11. Kapada Baby (Baby Mery, Baby Osulinda, dan Baby Ayu) Kosan Mayumi 20 yang selalu memberikan dukungan dan saran kepada penulis dari mulai sempro hingga penulis dapat menyelesaikan skripsi ini.

12. Kepada seluruh teman-teman Fakultas Syariah Angkatan 2018, yang mana tampa support mereka penulis tidak mungkin dapat membereskan skripsi ini dengan tepat waktu Dan kepada semua pihak-pihak yang tidak dapat disebutkan satu persatu dan sudah memberikan dukungan kepada penulis selama penulis mengerjakan skripsi ini hingga penulis dapat menyelesaikannya.

\section{Daftar Pustaka}

[1] Firmansyah, h. (2019). Qawaid Fiqhiyyah Dalam Fatwa Majelis Ulama Indonesia. ALQadha, 1-11

[2] Muhyddin. (2014). Fatwa MUI tentang Vasektomi Tanggapan Ulama dan Dampak terhadap Peningkatan Medis Operasi Pria (MOP). AL-AHKAM: jurnal pemikiran hukum islam, 69-92.

[3] Muslim, H. (2020). Pemikiran Ibnu Qayyim Al-Jauziyah (W751H/1350M) tentang Perubahan Fatwa dan Relevansinya dengan Perubahan Hukum Islam di Indonesia. ALMASHLAHAH: Jurnal hukum islam dan pranata sosial islam.

[4] Natangin. (2019). Vasektomi Dan Tubektomi Perspektif Maqasid Al-Syarial. ALHAKIM, 53-67

[5] Sari, E. (2019). Keluarga Berencana Perspektif Ulama Hadis. SALAM: Jurnal sosialdan budaya, 55-70. 